\title{
EDITORIAL
}

\section{ESTUDIOS DE COMUNICACIÓN POLITIICA DESDE UNA VISIÓN MÚLTIPLE}

\author{
Dr. Carlos Muñiz \\ Universidad Autónoma de Nuevo León, México \\ carlos.munizm@uanl.mx \\ ORCID iD: https://orcid.org/0000-0002-9021-8198
}

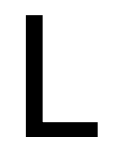

a relación entre comunicación y política, más allá de ser estática, se encuentra en constante proceso de evolución, al infiltrase en casi todos los espacios y contextos de relación entre los diferentes actores que se involucran en la esfera pública. Ello ha llevado a que, en la actualidad, imposible entender la labor y desempeño de esos actores del sistema político sin la utilización de estrategias de comunicación. Bien sea para hacer llegar a la ciudadanía sus propuestas, ideas y establecer su imagen pública, pero también para recibir retroalimentación de esa ciudadanía, la comunicación constituye una herramienta esencial en la relación gobernantes-gobernados. Sobre todo, a partir de la llegada de los nuevos medios, que implican una mayor difusión, rapidez y bilateralidad en la relación entre los diferentes actores. En este escenario, se advierte como muy actual la definición hecha en los años setenta del siglo pasado por Steven Chaffee (1975) acerca de la comunicación política, al definirla de una manera simple, pero muy completa, como el "papel de la comunicación dentro del proceso político" (p. 15). Y es que, más allá de la actividad de los medios masivos en su trabajo de selección y traducción de la realidad política, la comunicación política se adentra en cualquier tipo de relación entre los actores involucrados en esa esfera, a través de los diferentes medios con que en la actualidad se cuenta para comunicarse.

Nos encontramos, por tanto, ante un campo multidisciplinario, con múltiples influencias teóricas y metodológicas a lo largo de su historia, y en donde confluyen investigadores provenientes de diferentes perspectivas, escuelas y paradigmas. Así lo pusieron de manifiesto recientemente Jamieson y Kenski (2017), al tildar la comunicación política como un campo híbrido, que mantiene relaciones claras con otros campos como la sociología política, psicología política, neurociencia, ciencia política, etc. Una realidad que, más allá de suponer un inconveniente, debe constituir una de las mayores fortalezas, al permitir el campo el diálogo y trabajo fructífero de científicos con diferentes visiones y perspectivas sobre la realidad. Por ello, su estudio requiere necesariamente de esa mirada múltiple, variada y amplia, que permita comprender los fenómenos que se desarrollan en el terreno político, en especial en aquellos en los que la comunicación se ve involucrada. Algo a lo que el monográfico sobre comunicación política de la revista Perspectivas de la Comunicación que aquí se presenta ha tratado de contribuir. 
En el primer artículo, Arthur Ituassu, Letícia Capone, Leornardo Magalhães, Vivian Mannheimer y Felipe Murta proponen un ejercicio de reflexión acerca del impacto que la práctica de comunicación política en el ámbito digital durante las campañas electoral puede tener en el desarrollo de la democracia. Para ello, toman como casos de estudio dos procesos electorales, diferentes, pero con puntos de conexión: por una parte, la campaña electoral de Estados Unidos de 2016 que supuso la victoria de Donald Trump, y por otra las elecciones brasileñas de 2018 que llevaron a la presidencia a Jair Bolsonaro. Partiendo del concepto de "campaña hipermedia" -una evolución de los anteriores tipos de proceso de configuración de los procesos electorales como la americanización, modernización o posmodernización-, los autores plantean que actualmente nos encontramos en un contexto de campañas hipermediatizadas extendidas. Estas campañas ya no se ciñen a los períodos tasados para las elecciones, sino que se producen en el día a día de la gestión política, vienen marcadas por el uso fuerte de los nuevos medios e incluyen una fuerte propagación de información, pero también de desinformación política. A ello, los autores unen un interesante debate acerca del impacto que las nuevas campañas pueden estar teniendo en la ciudadanía, derivado del proceso de atomización en micropúblicos que el uso de los nuevos medios conlleva.

Quizá una de las temáticas más ampliamente trabajadas dentro de los estudios de comunicación política sea la cobertura realizada por los medios de comunicación de los procesos electorales. Es precisamente en esta línea donde se enmarca el trabajo que presentan en su artículo José Luis Estrada y Angélica Mendieta, cuyo objetivo es analizar la cobertura mediática realizada de las candidaturas a diputadas federales y senadoras durante la campaña electoral mexicana de 2018. Partiendo de los estudios precedentes acerca de la representación mediática de género en relación con la política, los autores repasan los datos relativos a la información presentada en noticieros de campaña a nivel nacional, pero también la publicidad y anuncios presentados en los medios. El análisis de los datos disponibles acerca de la campaña pone de manifiesta, señalan los autores, que los medios siguen reproduciendo los esquemas tradicionales de rol de la mujer, con contenidos que evocan la presentación de roles estereotipados. Además, aunque la legislación mexicana ha generado instrumentos para logar y garantizar una representación equitativa en la designación de candidaturas entre hombres y mujeres, los resultados revelan cómo esta equidad sigue sin plasmarse en el acceso a los medios a través de la presencia de candidatas y candidatos en los espacios publicitarios.

También en el contexto de la campaña electoral mexicana de 2018 se centra el trabajo de investigación que presentan en su artículo Victoria Isabela Corduneanu, Carlos Muñiz y Martín Echeverría. A partir de los datos obtenidos en una encuesta panel realizada en tres olas -antes, durante y después de la campaña electoral-, los autores evalúan el cambio en el tiempo de ciertas emociones hacia la política y prácticas de participación de bajo costo, como es la atención política en medios, entre la ciudadanía mexicana. Junto a ello, el artículo también busca determinar la posible relación explicativa entre las emociones sentidas y el desarrollo de esa 
actividad política considerada de bajo costo. Los autores parten en su trabajo de la importancia que las emociones juegan en la sociedad, asumiendo que ninguna acción puede ocurrir sin la implicación emocional de los actores, algo que también sucede en la esfera política. A partir de diferentes correlaciones desfasadas en el tiempo, los autores logran determinar el impacto en el tiempo de la atención a política en medios en el incremento de las emociones, aunque con un claro efector moderador de esta relación ejercido por parte de la cercanía partidista mantenida por los ciudadanos.

Son muchas las líneas de trabajo y estudio que implica en la actualidad la comunicación política, pero, sin duda, la afectación que los nuevos medios -medios y redes sociales- tienen en la esfera política constituye una de las más actuales y fructíferas en el campo. Precisamente dentro de este campo de estudio se enmarca el trabajo presentado por Sergio Octavio Contreras, acerca de las nuevas formas de acción colectiva realizadas a través de la red, así como de la percepción que los usuarios de estos nuevos medios tienen de la política. Para ello, el autor toma como caso de estudio la presencia en internet del colectivo \#YoSoy132, que emergió en las redes sociales durante la campaña electoral presidencial de México de 2012. A partir del análisis de la presencia del movimiento en las redes, el artículo busca identificar los elementos que posibilitan la comunicación política a través de la red. A partir del Análisis de Redes Sociales (ARS), el artículo pone de manifiesto cómo fueron pocos los participantes más activos que, aun así, consiguieron dar cohesión a la colectividad en línea. Esto lleva al autor a debatir sobre las posibles características de la comunicación en red, que viene marcada por la horizontalidad frente a la heterarquía, como parece ser este caso.

Si bien los trabajos de comunicación política mantienen el estudio de la cobertura mediática de los períodos electorales o en la influencia mediática sobre las actitudes políticas de la ciudadanía como líneas preferentes, cabe mencionar que existen otras áreas de trabajo que igualmente se desarrollan dentro de este campo disciplinar. Es el caso de la comunicación institucional o gubernamental, en la que se enmarca el trabajo presentado por Hilda Gabriela Hernández, Verónica Sánchez y Andrea Estupiñán. En su artículo, las autoras se adentran en el análisis de la comunicación como herramienta utilizada para crear y preservar la imagen y reputación gubernamentales, a partir de un caso paradigmático mexicano, como fue la crisis provocada por el terremoto que sufrió el país el 19 de septiembre de 2017. Pero, y más en concreto, las autoras revisan la acción comunicativa desarrollada por las instituciones públicas a raíz del caso de la niña Frida Sofía, supuestamente atrapada bajo los escombros provocados por el sismo, pero que resultó no existir. Los resultados del análisis permiten a las autoras reflexionar acerca del discurso que cualquier organización gubernamental debe mantener ante situaciones como la estudiada, que debe apegarse a la veracidad, pertinencia y cantidad adecuada de información para evitar ambigüedad en lo transmitido a la ciudadanía. 
El número especial se cierra con el artículo presentado por Emilia Lopera, que se adentra en análisis de las estrategias discursivas seguidas por la clase política para estructurar el debate acerca de los asuntos constitutivos de las políticas públicas de los países. En el caso concreto del trabajo presentado, la autora se centra en analizar los discursos parlamentarios de España que se han desarrollado durante el período democrático posterior a la constitución de 1978 en torno a las terapias alternativas y complementarias (TAC), evaluando cómo a lo largo de este tiempo ha evolucionado la construcción del discurso político en torno a esta temática. A partir de un análisis de contenido y un análisis del discurso de los 80 expedientes detectados en el Congreso de los Diputados y el Senado de España sobre las TAC, el trabajo permite observar cómo la estrategia discursiva parlamentaria osciló en los años entre una orientación pluralista de visiones en torno a las TAC y una orientación oposicionista, presente en mayor medida en los últimos años. La autora señala igualmente cómo al respecto de este debate el discurso mediático realizado en el período analizado permeó hacia el discurso parlamentario, lo que pone de manifiesto la capacidad de los medios para imponer agenda y tratamiento del asunto en el propio discurso realizado por los políticos.

Nos encontramos, por tanto, ante un número especial de Perspectivas de la Comunicación que aporta un conjunto de trabajos diversos que presentan una riqueza de visiones y metodologías en diferentes líneas de trabajo dentro de la comunicación política. Con estos trabajos, se espera contribuir a la reflexión y debate acerca de la generación de actitudes, opiniones y comportamientos que se manifiestan en la actualidad en la opinión pública y del papel que los medios, a través de su estrategia de cobertura de la política, tienen en su definición, tanto en contextos electorales, como fuera de estos. Por ello, solamente resta trasladar el mayor de los agradecimientos a los autores de los diferentes trabajos de este número, así como a los evaluadores convocados por sus aportaciones de mejora de los diferentes artículos publicados y, sin duda alguna, a los lectores de la revista.

Carlos Muñiz

Coordinador del número. 